\title{
Corticotrophin-releasing hormone and human parturition
}

\author{
Mark McLean ${ }^{1}$ and Roger Smith ${ }^{2}$ \\ ${ }^{1}$ Department of Diabetes and Endocrinology, Westmead Hospital, Sydney NSW 2145, \\ Australia; and ${ }^{2}$ Mothers and Babies Research Centre, Endocrine Unit, John Hunter Hospital, \\ Locked Bag 1, Hunter Region Mail Centre, Newcastle NSW 2310, Australia
}

\begin{abstract}
Corticotrophin-releasing hormone $(\mathrm{CRH})$, the hypothalamic peptide that controls function of the pituitary-adrenal axis in response to stress, is expressed in abundance in the human placenta and is present in high concentrations in maternal and fetal plasma during late pregnancy. A number of lines of evidence now imply a role for this hormone in the control of parturition and fetal maturation in humans. It has been proposed that $\mathrm{CRH}$, through interactions with oestrogen, adrenal steroids, prostaglandins and oxytocin, establishes positive-feedback loops that initiate parturition and labour. Excessive production of placental CRH has also been linked to preterm labour. However, there are a number of significant gaps in our knowledge of the function of this peptide in pregnancy. This review examines current evidence regarding the putative role of $\mathrm{CRH}$ in human parturition.
\end{abstract}

Corticotrophin-releasing hormone $(\mathrm{CRH})$ is a 41 amino acid peptide hormone first identified in the hypothalamus of mammals, where it acts as the main physiological regulator of corticotrophin (ACTH) secretion from corticotropes of the anterior pituitary (Vale et al., 1981). Hypothalamic secretion of $\mathrm{CRH}$ is stimulated by many forms of physical or psychological duress and $\mathrm{CRH}$ plays a critical role in co-ordination of the neuroendocrine response to stress. However, in addition to its function in the hypothalamicpituitary-adrenal axis, expression of the gene encoding $\mathrm{CRH}$ has now been recognized at a number of other sites, where it serves disparate roles. CRH acts as a neurotransmitter in some regions of the central nervous system (CNS), particularly those responsible for the neuropsychological responses to stress (Lenz et al., 1987), and CRH is also produced in a variety of tissues outside the CNS, including the gut, ovary and testis (Shibasaki et al., 1982; Suda et al., 1984). During human pregnancy, the placenta and fetal membranes produce large amounts of $\mathrm{CRH}$. Synthesis of $\mathrm{CRH}$ in these tissues increases exponentially with advancing gestation and, by term, it is present in high concentrations in the maternal and fetal blood, and in amniotic fluid. A considerable body of evidence now indicates a role for placenta-derived $\mathrm{CRH}$ in the physiology of human pregnancy, particularly in the process of parturition.

\section{Corticotrophin-releasing hormone and the placenta}

Placental corticotrophin-releasing hormone production

Shortly after the identification of CRH in the hypothalamus, $\mathrm{CRH}$ immunoreactivity and bioactivity were recognized

Email:mdrsm@mail.newcastle.edu.au in the human placenta (Shibasaki et al., 1982). The placenta also expresses the gene encoding CRH (Grino et al., 1987) and the concentration of the peptide and its mRNA in the placenta increases with advancing gestation, paralleling an exponential increase in maternal plasma $\mathrm{CRH}$ concentrations. Immunohistochemistry and in situ hybridization studies have localized CRH production to the syncytiotrophoblast of placental villi, the amniotic epithelium, trophoblast cells of the chorion, and the decidual stroma (Riley et al., 1991; Petraglia et al., 1992; Challis et al., 1995). Gel filtration studies show that most CRH present in placental extracts is the same 41 -amino acid peptide that is expressed in the hypothalamus. In addition, the placenta contains a larger molecular weight precursor, pre-pro-CRH, which is also biologically active (Chan et al., 1988).

\section{Control of placental corticotrophin-releasing hormone secretion}

Placental $\mathrm{CRH}$ output increases exponentially as pregnancy advances owing to specific upregulation of placental CRH gene expression (Frim et al., 1988). Although $\mathrm{CRH}$ release from the hypothalamus is predominantly under neural control, there is no nervous tissue in the placenta and placental $\mathrm{CRH}$ secretion is probably regulated exclusively by circulating and locally produced humoral factors. Several studies that used either cultured placental trophoblasts or perifused placental villous tissue showed secretion of $\mathrm{CRH}$ in vitro (Grino et al., 1987; Saijonmaa et al., 1988) that can be stimulated by a number of neurotransmitters, cytokines, and polypeptide or steroid hormones. In particular, prostaglandins $\mathrm{E}_{2}$ and $\mathrm{F}_{2 \alpha^{\prime}}$ noradrenalin, interleukin 1 (IL-1) and oxytocin all increase $\mathrm{CRH}$ release from cultured human syncytiotrophoblasts (Petraglia et al., 1989, 1990). In addition, 
glucocorticoids potently increase production of $\mathrm{CRH}$ mRNA and peptide from placental cells (Robinson et al., 1988; Jones et al., 1989) in marked contrast to their effect in the hypothalamus, where cortisol inhibits CRH synthesis and release. The positive feedback effect of glucocorticoids on placental CRH may be of great significance in parturition (see below). Progesterone inhibits placental CRH secretion in vitro (Petraglia et al., 1989), as do nitric oxide donors such as sodium nitroprusside (Sun et al., 1994).

\section{Corticotrophin-releasing hormone in the maternal circulation}

Hypothalamic CRH has a local effect on the anterior pituitary after passage through the hypothalamic-pituitary portal blood vessels but, in non-pregnant women, $\mathrm{CRH}$ is virtually undetectable in the peripheral blood, at concentrations of about $10-20 \mathrm{pg} \mathrm{ml}^{-1}$. As a consequence of the exponential increase in placental $\mathrm{CRH}$ output during pregnancy, maternal plasma $\mathrm{CRH}$ concentrations increase progressively to peak values at term and in labour of 1000-10000 pg ml-1, which is similar to the concentration found in the hypothalamic-pituitary portal blood during stress (Goland et al., 1986; Sasaki et al., 1987; Wolfe et al., 1988a). This high maternal plasma CRH concentration is constantly maintained (unlike the episodic CRH secretion from the hypothalamus), is not subject to diurnal variation, and does not fluctuate in response to stress (Petraglia et al., 1994; Magiakou et al., 1996).

\section{Biological actions of corticotrophin-releasing hormone in pregnancy}

\section{Maternal pituitary-adrenal axis}

If a non-pregnant woman is given an intravenous bolus injection of $\mathrm{CRH}$ to achieve a plasma $\mathrm{CRH}$ concentration equivalent to that of a term pregnant woman, there is a prompt release of ACTH from the pituitary, and thence cortisol from the adrenal cortex (Schurmeyer et al., 1984). It might be expected that the very high concentration of circulating $\mathrm{CRH}$ in pregnancy would produce sustained stimulation of the maternal pituitary-adrenal axis, but this is not the case. Although pregnancy is characterized by mild hypercortisolism, this is predominantly a result of an oestrogen-induced increase in cortisol-binding globulin, and the circadian rhythm of ACTH and cortisol secretion is retained throughout pregnancy (Nolten and Rueckert, 1981; Scott et al., 1990). There is also a normal cortisol response to stress, for example, during surgery, and a marked increase in plasma cortisol concentrations at the time of labour (Namba et al., 1980; Nolten et al., 1980). It seems that the physiological function of placental CRH is not related to the maternal pituitary-adrenal axis and recent research has addressed other possible roles for this peptide in pregnancy. In view of the particularly high concentrations of $\mathrm{CRH}$ in late pregnancy, much work has focused on a possible role of $\mathrm{CRH}$ in parturition.

\section{Fetal pituitary-adrenal axis}

The human fetus has a functioning pituitary-adrenal axis by mid-trimester. Placental $\mathrm{CRH}$ is released into the fetal circulation where, although present in concentrations about tenfold lower than in the maternal blood, it is capable of stimulating ACTH secretion from the fetal pituitary. Further $\mathrm{ACTH}$ is synthesized within the placenta under the influence of paracrine stimulation by $\mathrm{CRH}$ (Petraglia et al., 1987; Margioris et al., 1988). In the fetus, ACTH derived from the pituitary and the placenta stimulates steroidogenesis in the fetal adrenal. The principal products of the fetal adrenal gland are cortisol and the androgenic steroids dehydroepiandrosterone (DHEA) and its sulphate (DHEAS). Cortisol secretion is potently induced by ACTH and an increase in fetal cortisol production in late pregnancy is an important factor in the promotion of fetal organ maturation before delivery (Fencl et al., 1980). DHEA and DHEA-S are synthesized in the specialized fetal zone of the adrenal, which forms more than $50 \%$ of the adrenal mass in late fetal life, but which involutes completely shortly after delivery. The fetal zone is responsive to stimulation directly by $\mathrm{CRH}$, independently of ACTH, with CRH stimulating secretion of DHEA and DHEA-S from the fetal adrenal in a dosedependent manner (Smith et al., 1998). The significance of these findings in vitro for the physiology of the fetus is still uncertain. In particular there are few data regarding the normal concentrations of $\mathrm{CRH}$ in the fetal plasma before labour and therefore it is not proven that the observed actions of $\mathrm{CRH}$ on the fetal pituitary and adrenal occur at physiological concentrations. The influence of $\mathrm{CRH}$ binding protein (CRH-BP, see below) or other inhibitors of $\mathrm{CRH}$ action in the fetus are also unknown. However, placental CRH may act as a promoter of hypertrophy of the fetal zone during pregnancy, and the sudden withdrawal of $\mathrm{CRH}$ at delivery may be the event that leads to its post-natal disappearance. In humans, production of DHEA and DHEA-S in the fetal zone is a significant link in the events leading to initiation of parturition. These androgenic steroids are taken up by the placenta and form $80-90 \%$ of the substrate for placental synthesis of oestrogen (Challis and Olson, 1988), which in turn acts in the maternal compartment to promote the onset of labour through its actions on the myometrium, cervix and fetal membranes.

The actions of $\mathrm{CRH}$ in sheep fetuses have been demonstrated elegantly in two sets of experiments by different researchers. Wintour et al. (1986) showed that long-term infusion of $\mathrm{CRH}$ into the fetus resulted in premature activation of the fetal pituitary-adrenal axis, accelerated maturation of a number of fetal organs and spontaneous preterm delivery of viable lambs. The converse experiment, prolonged infusion of a $\mathrm{CRH}$ antagonist into sheep fetuses, resulted in significant prolongation of pregnancy beyond term (Chan et al., 1998). However, these data cannot necessarily be extrapolated to human pregnancy since there are a number of important differences 
between the species, including the absence of a circulating $\mathrm{CRH}-\mathrm{BP}$ or a fetal adrenal zone in sheep, and significantly lower expression of $\mathrm{CRH}$ in the ovine compared with the human placenta.

\section{Fetal membranes and amniotic fluid}

$\mathrm{CRH}$ is expressed in all layers of the fetal membranes and is present in amniotic fluid (Okamoto et al., 1990a,b; Riley et al., 1991). The CRH concentration of amniotic fluid increases with advancing gestational age, but less steeply than the maternal plasma concentrations. In early pregnancy, the amniotic fluid concentration is approximately equal to that of the maternal plasma but in late pregnancy and at term, it is similar to that of fetal blood and considerably lower than in the maternal circulation (Laatikainen et al., 1988; Sasaki et al., 1990). There is an important potential interaction between $\mathrm{CRH}$ and prostaglandin (PG) production in the amniotic compartment. Synthesis of $\mathrm{PGE}_{2}$ and $\mathrm{PGF}_{2 \alpha}$, potent promoters of cervical maturation and uterine contractility, is induced by $\mathrm{CRH}$ in preparations at physiological concentrations in vitro (Jones and Challis, 1989). These prostaglandins are capable of promoting further $\mathrm{CRH}$ secretion by the placenta and fetal membranes (Petraglia et al., 1989, 1996), resulting in the formation of a positive feedback loop. CRH also stimulates output of interleukin 6 from peripheral blood mononuclear cells, which infiltrate the fetal membranes, placenta and cervix in increasing numbers during parturition and intrauterine infection (Angioni et al., 1993). IL-6 and IL-1, in turn, have been shown to stimulate $\mathrm{CRH}$ release from cultured human placental trophoblasts in vitro (Petraglia et al., 1990).

\section{Myometrium}

During parturition, a number of important cellular changes occur in the uterine smooth muscle in preparation for labour, including the development of gap junctions between adjacent muscle cells, activation of pacemaker cells that initiate spontaneous contractions, and expression of receptors for uterotonins such as oxytocin and prostaglandins. The most important stimulus to these changes in the myometrium is oestrogen, the formation of which is linked indirectly to $\mathrm{CRH}$ in the placenta and fetus as outlined above. A possible direct action of $\mathrm{CRH}$ on uterine smooth muscle has also been the subject of considerable research. Quatero and Fry (1989) used strips of human myometrium obtained at Caesarean section to study the effects of $\mathrm{CRH}$ on electrically stimulated myometrial contractility. Although $\mathrm{CRH}$ alone had no influence on smooth muscle contraction, the presence of $\mathrm{CRH}$ (or preincubation with $\mathrm{CRH}$ ) resulted in a greatly enhanced response of the myometrial strips to the uterotonic effect of oxytocin (Quartero and Fry, 1989). A similar enhancement by $\mathrm{CRH}$ of $\mathrm{PGE}_{2}$-mediated myometrial contractility has also been demonstrated (Benedetto et al., 1994). Two clinical studies have found an inverse relationship between the maternal plasma $\mathrm{CRH}$ concentration and the duration of labour during either spontaneous or induced labour in women (Stalla et al., 1989; McLean et al., 1994).

$\mathrm{CRH}$ receptors $(\mathrm{CRH}-\mathrm{r})$ are expressed in the human myometrium and their numbers and binding affinity increase greatly during pregnancy (Hillhouse et al., 1993). A variety of different molecular species of $\mathrm{CRH}$-r are present in different tissues, with differing second messenger systems. The pituitary $\mathrm{CRH}-\mathrm{r}$ is coupled through a stimulatory Gprotein (Gs) to the adenylate cyclase-CAMP-protein kinase $\mathrm{A}$ (PKA) signalling pathway. If this receptor is present in the myometrium, $\mathrm{CRH}$ would promote muscle relaxation. However, in non-pituitary tissues, other $\mathrm{CRH}-\mathrm{r}$ isoforms have been identified which couple to the phospholipase C-inositol phosphate-protein kinase C (PKC) second messenger system (Ulisse et al., 1990; Chakravorty et al., 1999). In the myometrium, this receptor would lead to a $\mathrm{CRH}$-stimulated increase in intracellular calcium and promote contraction. Using a radio-receptor assay, isoelectric focusing and autoradiography, Grammatopoulos et al. (1995) identified five isoforms of CRH-r in human myometrium with different physicochemical characteristics. The functional significance and second messenger coupling of the different subtypes expressed in pregnant myometrium is not known. However, during pregnancy, the human myometrium appears to express different types of $\mathrm{CRH}-\mathrm{r}$ at different stages of gestation. Before term, $\mathrm{CRH}$ signalling in the myometrium is predominantly via Gs-PKA (that is, it is pro-relaxation), but there is a significant decrease in the coupling of the human myometrial CRH-r to adenylate cyclase at term (Grammatopoulos et al., 1996), possibly as a result of oxytocin-induced phosphorylation of these CRH-r isoforms (Grammatopoulos and Hillhouse, 1999), leading to withdrawal of CRH-mediated relaxation of uterine muscle at term. However, currently, there is no evidence demonstrating linkage of myometrial $\mathrm{CRH}-\mathrm{r}$ to cellular processes that favour contraction.

\section{Positive-feedback circuits in human parturition}

Challis and Hooper (1989) outlined the novel concept of a series of positive-feedback circuits promoting parturition. In this model, placental CRH promotes fetal cortisol and DHEA-S production, and these steroids return via the umbilical circulation to the placenta, where cortisol promotes further CRH secretion (Fig. 1). Once established, this positive feedback loop would be progressively amplified and drive the fetal-placental unit inexorably towards the final outcome of fetal maturation and delivery. In cases of fetal distress or compromise (for example, from intrauterine infection or hypoxia), activation of the fetal pituitary-adrenal axis in response to stress may accelerate fetal organ maturation and feedback to the placenta to increase CRH secretion and promote the onset of parturition, providing a means of escape from a threat to fetal survival in utero. A second feed-forward circuit is established in the amniotic compartment where $\mathrm{CRH}$ and prostaglandins promote production of each other. Positive 


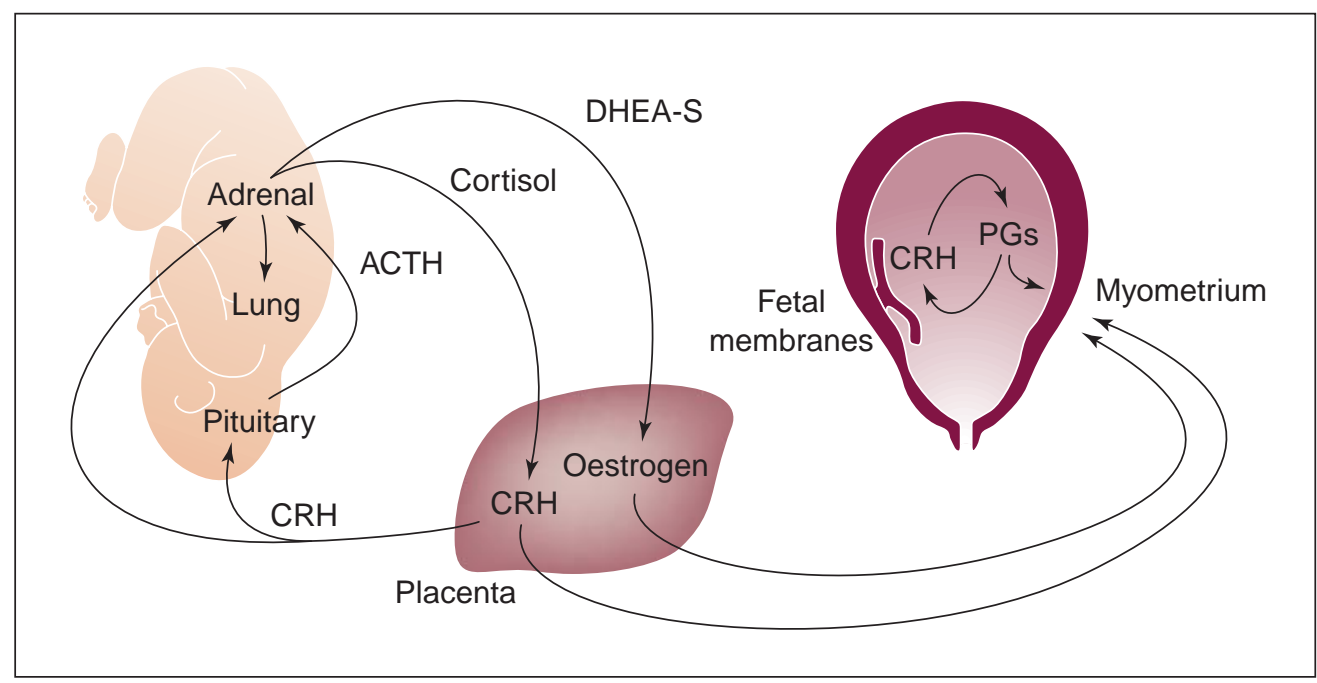

Fig. 1. Interacting positive-feedback hormonal loops in the fetal, amniotic and maternal compartments that may promote the progression of fetal maturation and initiation of parturition in humans. Each of the arrows represents a stimulatory action of the indicated hormone. ACTH: adrenocorticotrophin; $\mathrm{CRH}$ : corticotrophin-releasing hormone; DHEA-S: dehydroepiandrosterone sulphate; PGs: prostaglandins.

feedback loops are very uncommon in physiological systems. However, in the initiation of labour, a positive feedback loop has distinct theoretical advantages. The hormonal signals promoting parturition will be progressively amplified until labour and delivery occur and the only way these amplification loops can be broken is by delivery of the fetus and placenta (Fig. 1). The onset of parturition may occur as a result of a shift from a hormonal system promoting uterine quiescence (a negative feedback system) to the positive feedback circuit outlined above. However, the mechanism of such a 'switch' is unknown. Although this model is consistent with many of the events known to occur during human parturition, it is not necessarily preferable to, or exclusive of, other hypotheses. Parturition is a complex process in which many other hormonal factors play a part.

\section{Corticotrophin-releasing hormone-binding protein}

Human plasma contains a binding protein for $\mathrm{CRH}(\mathrm{CRH}-$ $\mathrm{BP})$ that couples to the peptide with high affinity in a $1: 1$ molecular interaction and prevents its recognition and activation of the $\mathrm{CRH}$ receptor. Therefore, $\mathrm{CRH}-\mathrm{BP}$ blocks the bioactivity of $\mathrm{CRH}$ in the circulation. $\mathrm{CRH}-\mathrm{BP}$ is the only known specific binding protein for a neuropeptide and, while numerous hormone-carrying proteins have been recognized, including some for peptide hormones (for example, insulin-like growth factors), CRH-BP has an important unique feature. Other binding proteins serve to prolong the circulating half-life of their ligands but CRH-BP appears to do the opposite (Saphier et al., 1992). Association of $\mathrm{CRH}-\mathrm{BP}$ with its ligand triggers dimerization of the complex, which is then rapidly cleared from the circulation (Woods et al., 1994a). Infusion of CRH into non-pregnant women induces a rapid decrease in the circulating $\mathrm{CRH}-\mathrm{BP}$ concentration (Woods et al., 1994b). A radioimmunoassay for CRH-BP was developed by Linton and Lowry (Linton et al., 1993) and has been used by the present authors and others to investigate changes in plasma CRH-BP concentrations during pregnancy (Perkins et al., 1993; McLean et al., 1995). During most of pregnancy, CRH-BP is present in the maternal plasma at a concentration that greatly exceeds that of $\mathrm{CRH}$, thereby making circulating $\mathrm{CRH}$ largely biologically inactive. However, in the final few weeks of pregnancy, co-incident with the rapid increase in plasma $\mathrm{CRH}$, there is a simultaneous decrease in the plasma $\mathrm{CRH}-\mathrm{BP}$ concentration of approximately $50 \%$ to a nadir at delivery (Linton et al., 1993) (Fig. 2). CRH-BP returns to normal non-pregnant concentrations within $48 \mathrm{~h}$ after delivery. Only in the final 3 weeks of gestation is $\mathrm{CRH}$ present in sufficient concentration in maternal plasma to fully saturate $\mathrm{CRH}-\mathrm{BP}$, resulting in the sudden appearance at that time of free $\mathrm{CRH}$, which is biologically active (Behan et al., 1996). This is the stage of gestation at which most of the cellular changes of parturition are initiated in the myometrium, fetal membranes, cervix and fetus and we have suggested that the saturation of circulating CRH-BP and the consequent availability of free $\mathrm{CRH}$ in late pregnancy may be a mechanism contributing to the triggering of parturition in humans (McLean et al., 1995).

\section{Corticotrophin-releasing hormone and the timing of labour}

\section{Corticotrophin-releasing hormone in preterm labour}

An association between increased maternal plasma $\mathrm{CRH}$ and preterm labour was first noted in a cross-sectional study 
of 11 women admitted to hospital with preterm labour, whose plasma $\mathrm{CRH}$ concentrations were significantly higher than 80 gestational age-matched controls who were not in labour (Campbell et al., 1987). In a subsequent small longitudinal study, the same investigators noted above normal plasma CRH for up to 11 weeks before the onset of preterm labour, raising the possibility that it could be a useful predictive test (Wolfe et al., 1988b). Other crosssectional studies reported similar findings (Kurki et al., 1991; Warren et al., 1992). A more substantial longitudinal study by Wolfe et al. (1990) calculated the slope of the increase in plasma $\mathrm{CRH}$ for 168 individual subjects who had sequential plasma CRH estimations at 2-4 week intervals from 24 weeks of gestation until delivery. Women who delivered before 37 weeks $(n=15)$ had a steeper increase in $\mathrm{CRH}$ than women who delivered at term; the slope of the CRH curve was about 25\% higher in affected pregnancies. However, the small number of preterm deliveries in this study meant that the observed difference did not achieve statistical significance.

Our own longitudinal study, first reported in 1995 (485 pregnancies, 24 spontaneous preterm deliveries) and updated in 1999 (860 pregnancies, 60 preterm deliveries), was designed to test the association between early pregnancy maternal plasma $\mathrm{CRH}$ and the later timing of labour (McLean et al., 1995, 1999). When expressed as multiples of the median (MoM) value for normal pregnancies at the same gestational age, plasma CRH was threefold higher in women delivering preterm (median 3.25 MoM, 95\% Cl 1.99-4.26, $P<0.00005$ ), and 40\% lower in women delivering post-term (median MoM 0.61, 95\% Cl 0.48-0.82, $P<0.005)$ than in women delivering at term (median MoM 1.00, 95\% Cl 0.91-1.08). These differences were evident from 16-18 weeks of gestation, which is the earliest stage of pregnancy at which $\mathrm{CRH}$ can be measured in our assay. The diverging patterns of exponential increase in plasma $\mathrm{CRH}$ with gestation are shown in Figure 3. There was no difference in CRH-BP concentrations among women with premature, term or post-term deliveries. Two further longitudinal studies, in different study populations, have confirmed the association of high second trimester maternal plasma CRH concentrations with subsequent preterm labour and delivery (Hobel et al., 1999; Leung et al., 1999). A third study found a trend towards the same association but the effect was not significant (Berkowitz et al., 1996).

\section{'Placental clock' hypothesis}

It was surprising to find that different patterns of plasma $\mathrm{CRH}$ could be recognized by mid-trimester in women who subsequently experienced early, normal or late timing of delivery. These data indicate the existence of a progressive maturational process in the placenta that is established early in pregnancy, proceeds in a predictable fashion throughout gestation in most pregnancies, and is linked to the eventual timing of parturition. This phenomenon may be analogous

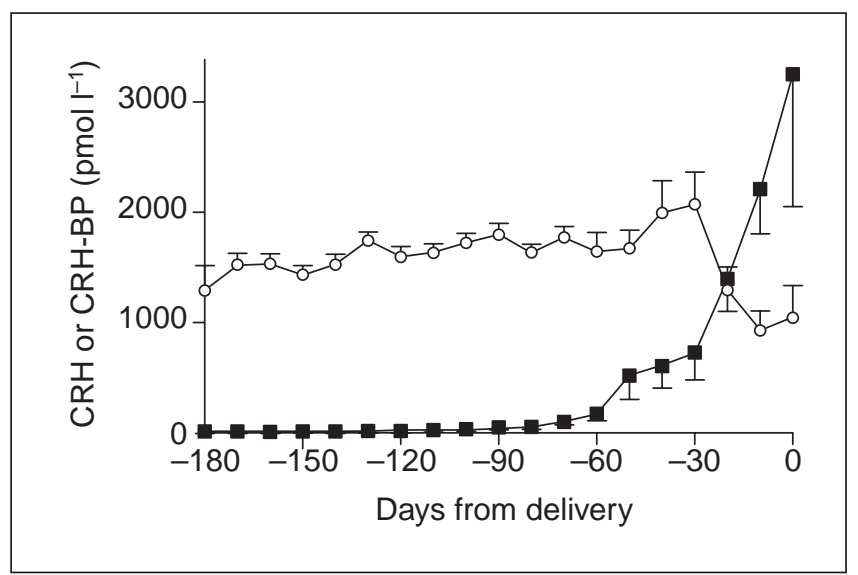

Fig. 2. Mean $( \pm \mathrm{SEM})$ concentrations of corticotrophin-releasing hormone $(\mathrm{CRH} ; \mathbf{\square})$ and $\mathrm{CRH}$-binding protein $(\mathrm{CRH}-\mathrm{BP} ; \mathrm{O})$ in maternal plasma in normal pregnancies ending in spontaneous term labour $(n=308)$. As pregnancy advances, maternal plasma $\mathrm{CRH}$ increases exponentially, but full saturation of the binding capacity of CRH-BP does not occur until about 20 days before delivery, when the $\mathrm{CRH}-\mathrm{BP}$ concentration also decreases by about $50 \%$. Therefore, free $\mathrm{CRH}$ is available at the time of parturition. (Reproduced, with permission, from McLean et al., 1995.)

to the 'placental clock' that triggers the onset of parturition after a predetermined duration of gestation, and appears to progress at different rates in individual pregnancies with some pregnancies 'programmed' for early or late delivery. Measurement of maternal plasma $\mathrm{CRH}$ provides a marker of the rate of this process in an individual (Fig. 3). However, $\mathrm{CRH}$ is not the only marker of this phenomenon since maternal plasma alpha-fetoprotein (AFP) concentrations are also associated with the timing of delivery, although less strongly than CRH (McLean et al., 1999). These findings challenge the previously held notion that the duration of human gestation is determined solely by events in late pregnancy and indicate that conditions leading to preterm or post-term delivery can be established early in gestation.

In the placental clock hypothesis, the rate of increase in maternal plasma $\mathrm{CRH}$ through pregnancy influences the timing of labour by determining when saturation of CRH-BP will be achieved and therefore when free $\mathrm{CRH}$ becomes available to act as a parturition trigger. This would occur prematurely if acceleration of the placental clock resulted in a shift of the CRH curve to the left, and would be delayed in women whose slower clock results in low CRH concentrations. Other placental processes unrelated to $\mathrm{CRH}$ may also be linked to a 'maturational timetable' leading to the onset of parturition. The important concept contained in the placental clock hypothesis is that, whether it be through the action of $\mathrm{CRH}$ or by other mechanisms, parturition results from a process begun very early in pregnancy and the rate of this process can be inferred from observation of specific biochemical markers. Many factors may affect the speed of the placental clock in an individual pregnancy, including genetic predisposition and pathological events in the 


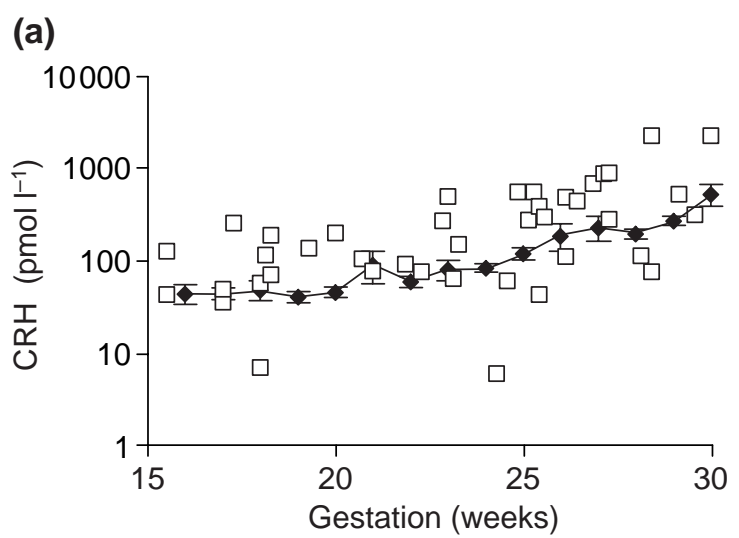

(b)
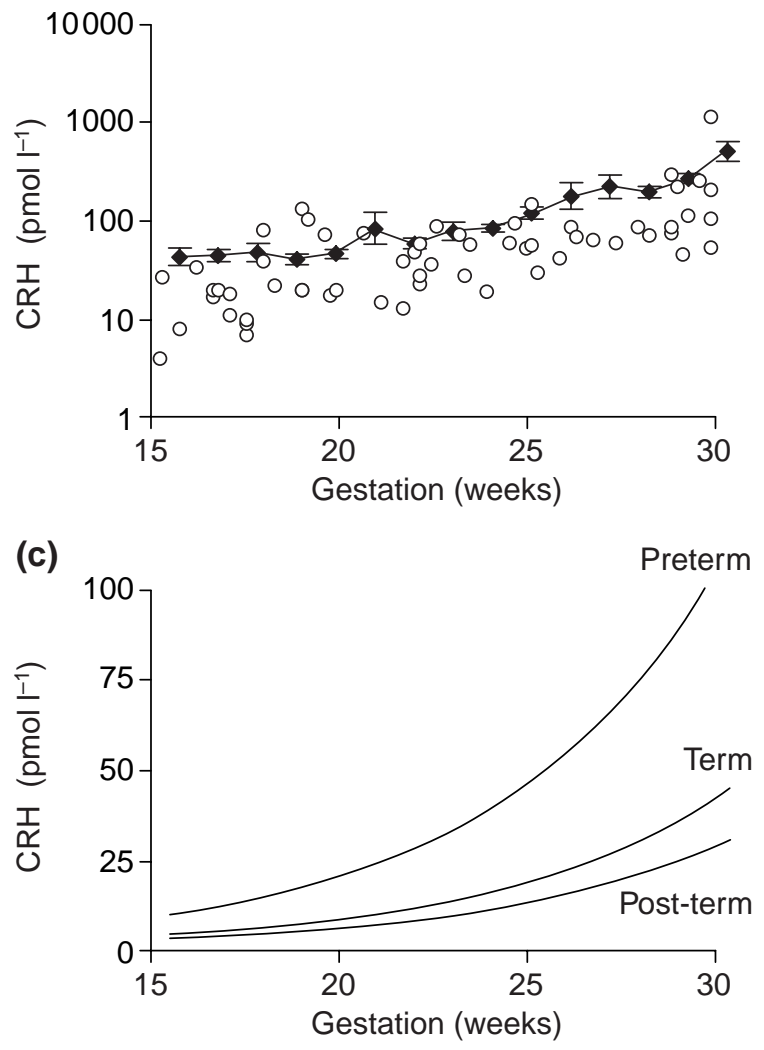

Fig. 3. Mean ( \pm SEM) plasma corticotrophin-releasing hormone $(\mathrm{CRH})$ (on log scale) in women with spontaneous term delivery $(\bullet$ $n=308$ ) compared with individual samples from women with (a) spontaneous preterm delivery $(\square, n=24$ ) or (b) post-term delivery $(\bigcirc, n=29)$. (c) Regression curves of maternal plasma CRH (on linear scale) versus gestation fitted to data from the three groups. (Reproduced, with permission, from McLean et al., 1995.)

mother or fetus. Individual women have a marked tendency to have the same gestational duration in subsequent pregnancies (Mittendorf et al., 1993; Mongelli and Opatola, 1995), indicating a predisposition which may have a genetic basis, although environmental factors also seem to be important in some women who experience repeated preterm deliveries.

Clearly, the placental clock would not be the sole determinant of the timing of delivery in women. Premature delivery does not necessarily represent an acceleration of the normal parturition process and pathological events such as infection may intervene to precipitate labour through alternative mechanisms. It is a consistent finding from a number of studies that preterm labour associated with intrauterine infection is characterized by low or normal maternal CRH concentrations while 'idiopathic' preterm labour is usually accompanied by increased plasma $\mathrm{CRH}$ concentrations (Warren et al., 1992; Korebrits et al., 1998; McLean et al., 1999).

\section{Inconsistencies and deficiencies in the data}

Although a considerable body of circumstantial evidence now links $\mathrm{CRH}$ with the process of parturition in humans, there are some significant gaps in the model. There is a paucity of data relating to the direct cellular and molecular actions of $\mathrm{CRH}$ in the putative target tissues such as the myometrium, fetal membranes and placenta. $\mathrm{CRH}$ receptors are expressed in these tissues but their characteristics are not yet well defined. A particular problem is the action of $\mathrm{CRH}$ in the myometrium, in which the only $\mathrm{CRH}$ receptors identified to date appear to be linked to the Gs-adenylate cyclase system. Therefore, CRH would be expected to promote muscle relaxation through an increase in intracellular cAMP: an action inconsistent with a role as a promoter of parturition. Alternative forms of $\mathrm{CRH}$ receptor have been shown in other human tissues to act through alternative second messenger systems, including some that increase intracellular calcium or activate the inositol phosphate-protein kinase C pathway (Ulisse et al., 1990; Chakravorty et al., 1999). If present in uterine smooth muscle, these receptors could theoretically mediate an action by $\mathrm{CRH}$ to promote contraction. Therefore, it has been hypothesized that the influence of $\mathrm{CRH}$ on the myometrium at term alternates from promotion of relaxation to favouring contraction through a change in $\mathrm{CRH}-\mathrm{r}$ isoforms (McLean and Smith, 1999). However, this suggestion is highly speculative and the absence of a proven link between $\mathrm{CRH}$ action and the onset of uterine contraction is the major flaw in the theory that $\mathrm{CRH}$ is a significant promoter of parturition.

There is very wide variability of plasma $\mathrm{CRH}$ concentration among individual women, even among those with normal pregnancies, which limits the accuracy with which plasma CRH measurements can be used to discriminate between normal and abnormal pregnancies. Preterm labour can occur as the final outcome of a diverse range of pathological processes, many of which appear to be independent of $\mathrm{CRH}$, indicating that high maternal plasma $\mathrm{CRH}$ concentrations are not requisite for initiation of labour.

The cellular mechanism of the putative placental clock is unknown. Factors regulating gene expression for the $\mathrm{CRH}$ 
precursor in the placenta are also poorly understood. Many other hormone systems have been implicated in human parturition, including oxytocin, relaxin, endothelins, nitric oxide, prostaglandins, and oestrogen-progesterone. There are many points of possible interaction of these hormones with each other and with $\mathrm{CRH}$, and few of these have been explored in detail.

\section{Species differences}

A significant difficulty in providing experimental data in this area is the wide variation in the physiology of pregnancy in different species. Although parturition may well be precipitated by the production of CRH by the fetal hypothalamus in many species, only in primates does significant production of CRH occur in the placenta (Robinson et al., 1989). Initial studies using northern blot analysis of primate placenta CRH mRNA and CRH mRNA from the placentas of a variety of other mammals demonstrated expression only in New and Old World monkeys and apes. Several studies in pregnant baboons have revealed that maternal plasma $\mathrm{CRH}$ increases rapidly in early pregnancy in this species and reaches peak values in the second third of pregnancy (60-80 days) before decreasing to concentrations that remain stable until delivery. This pattern is quite different from the exponential increase observed throughout human pregnancy (Goland et al., 1990; Smith et al., 1993). In limited studies in rhesus monkeys, increases in maternal plasma $\mathrm{CRH}$ appear to occur in the later part of pregnancy but detailed analysis of earlier stages of pregnancy are not available, and concentrations are generally lower than those in baboons. Studies in chimpanzees and gorillas have revealed patterns of $\mathrm{CRH}$ change in maternal blood indistinguishable from those in humans (Smith et al., 1999). No circulating binding protein for $\mathrm{CRH}$ is observed in baboons, but $\mathrm{CRH}-\mathrm{BP}$ is found in gorillas, in which the gestational age-related changes in this protein are virtually identical to those of humans. It appears that only in our closest relatives are the patterns of $\mathrm{CRH}$ production very similar to that seen in our own species.

\section{Clinical implications}

\section{Plasma corticotrophin-releasing hormone as a predictor of preterm delivery}

If plasma CRH is high in women destined to experience preterm delivery, can this be used to identify high-risk pregnancies and allow preventive intervention? In a prospective study of 860 women, plasma CRH and AFP were measured on one occasion between 16 and 24 weeks of gestation to assess their predictive accuracy for delivery before 37 weeks of gestation and this was compared with a clinical risk-factor score (McLean et al., 1999). Sixty women $(7 \%)$ delivered before 37 weeks of gestation (37 women after spontaneous preterm labour). If the upper limit of normal $\mathrm{CRH}$ and AFP concentrations is set at the 95th percentile for normal pregnancies (that is, allowing a $5 \%$ false positive rate), the detection rate (sensitivity) of plasma $\mathrm{CRH}$ and AFP measurements were low at 24 and $25 \%$, respectively, but both tests predicted more cases of preterm delivery than the risk-factor score. The best predictive information was obtained from an algorithm using all three results that predicted $37 \%$ of cases of preterm delivery with a false positive rate of $5 \%$. The odds of having a preterm delivery for women with a positive triple test was 1:1.7 (positive predictive value $37 \%$ ). This is the best test yet described for prediction of preterm delivery, but the detection rate is probably still too low for effective use as a routine clinical test.

\section{Corticotrophin-releasing hormone antagonists as inhibitors of parturition}

Peptide and non-peptide antagonists of the $\mathrm{CRH}$ receptor have now been developed and have shown activity in animal experiments. As yet, no studies have been performed in humans. A theoretical application of these drugs is the inhibition of $\mathrm{CRH}$-mediated effects in parturition. In the only study reported in pregnant animals, a CRH antagonist, antalarmin, was continuously infused directly into sheep fetuses during the final 5-10 days of gestation (term in sheep $=140$ days), resulting in a significant delay in spontaneous delivery of 7 days compared with placebo-treated animals (Chan et al., 1998). Administration directly into the fetus would be impractical in humans, and it is not known if initiation of treatment after the onset of parturition (for example, to a woman presenting in preterm labour) would have any effect on the progression of labour.

\section{Conclusions}

$\mathrm{CRH}$ has emerged as a leading contender for a role in the initiation and promotion of human parturition. Recent discoveries of the endocrinology of placental CRH have lead to a revision of some theories concerning the control of labour. Much is still unknown about the mechanism of its actions in pregnancy but exciting theories regarding receptor and second messenger actions in the myometrium are now being tested. Clinical applications of CRH research, although remote at present, may lead to improvements in our ability to prevent preterm birth, which is the leading cause of perinatal morbidity and mortality in developed countries.

\section{References}

Key references are identified by asterisks.

Angioni S, Petraglia F, Gallinelli A, Cossarizza A, Franceschi C, Muscettola M, Genazzani AD, Surico N and Genazzani AR (1993) Corticotropinreleasing hormone modulates cytokine release in cultured human peripheral blood mononuclear cells Life Sciences 53 1735-1742

Behan DP, Khongsaly O, Liu XJ, Ling N, Goland RS, Nasman B, Olsson T and De-Souza EB (1996) Measurement of corticotropin-releasing factor (CRF), CRF-binding protein (CRF-BP), and CRF/CRF-BP complex in human plasma by two-site enzyme-linked immunoabsorbant assay Journal of Clinical Endocrinology and Metabolism $812579-2586$ 
Benedetto C, Petraglia F and Marozio L (1994) Corticotropin-releasing hormone increases prostaglandin F2-alpha activity on human myometrium in vitro. American Journal of Obstetrics and Gynecology 171 126-131

Berkowitz GS, Lapinski RH, Lockwood CJ, Florio P, Blackmore-Prince C and Petraglia F (1996) Corticotropin-releasing factor and its binding protein: maternal serum levels in term and preterm deliveries American Journal of Obstetrics and Gynecology 174 1477-1483

Campbell EA, Linton EA, Wolfe CDA, Scraggs PR, Jones MT and Lowry PJ (1987) Plasma corticotrophin-releasing hormone concentrations during pregnancy and parturition Journal of Clinical Endocrinology and Metabolism 64 1054-1059

Chakravorty A, Mesiano S and Jaffe RB (1999) Corticotropin-releasing hormone stimulates $\mathrm{P} 450 \alpha$-hydroxylase/17,20-lyase in human fetal adrenal cells via protein kinase C Journal of Clinical Endocrinology and Metabolism 84 3732-3738

*Challis JRG and Hooper S (1989) Birth: outcome of a positive cascade Bailliere's Clinical Endocrinology and Metabolism 3 781-793

Challis JRG and Olson DM (1988) Parturition. In The Physiology of Reproduction pp 2177-2216 Eds E Knobil and J Neill. Raven Press, New York

Challis JRG, Matthews SG, Van Meir C and Ramirez MM (1995) The placental corticotrophin-releasing hormone-adrenocorticotrophin axis Placenta 16 481-502

Chan EC, Thomson M, Madsen G, Falconer J and Smith R (1988) Differential processing of corticotrophin-releasing hormone by the human placenta and hypothalamus Biochemical and Biophysical Research Communications 153 1229-1235

Chan EC, Falconer J, Madsen G, Rice KC, Webster EL, Chrousos GP and Smith R (1998) A corticotropin-releasing hormone type I receptor antagonist delays parturition in sheep Endocrinology 139 3357-3360

Fencl M, Sillman MRF, Cohen J and Tulchinsky D (1980) Direct evidence of a sudden rise in fetal corticoids late in human gestation Nature $\mathbf{2 8 7}$ 225-226

Frim DM, Emanuel RL, Robinson BG, Smas CM, Adler GK and Majzoub JA (1988) Characterization and gestational regulation of corticotropinreleasing hormone messenger RNA in human placenta Journal of Clinical Investigation 82 287-292

Goland RS, Wardlaw SL, Stark RI, Brown LSJ and Frantz AG (1986) High levels of corticotrophin-releasing hormone immunoactivity in maternal and fetal plasma during pregnancy Journal of Clinical Endocrinology and Metabolism 63 1199-1203

Goland RS, Stark RI and Wardlaw SL (1990) Response to corticotropinreleasing hormone during pregnancy in the baboon Journal of Clinical Endocrinology and Metabolism 70 925-929

Grammatopoulos DK and Hillhouse EW (1999) Role of corticotropinreleasing hormone in the onset of labour Lancet 354 1546-1549

Grammatopoulos D, Thompson S and Hillhouse EW (1995) The human myometrium expresses multiple isoforms of the corticotropin-releasing hormone receptor Journal of Clinical Endocrinology and Metabolism $\mathbf{8 0}$ 2388-2393

Grammatopoulos D, Stirrat GM, Williams SA and Hillhouse EW (1996) The biological activity of the corticotropin-releasing hormone receptoradenylate cyclase complex in human myometrium is reduced at the end of pregnancy Journal of Clinical Endocrinology and Metabolism 81 745-751

Grino M, Chrousos GP and Margioris AN (1987) The corticotropin releasing hormone gene is expressed in human placenta Biochemical and Biophysical Research Communications 148 1208-1214

Hillhouse EW, Grammatopoulos D, Milton NG and Quartero HW (1993) The identification of a human myometrial corticotropin-releasing hormone receptor that increases in affinity during pregnancy Journal of Clinical Endocrinology and Metabolism 76 736-741

Hobel CJ, Dunkel-Schetter C, Roesch SC, Castro LC and Arora CP (1999) Maternal plasma corticotropin-releasing hormone associated with stress at 20 weeks' gestation in pregnancies ending in preterm delivery American Journal of Obstetrics and Gynecology 180 S257-S263

Jones SA and Challis JRG (1989) Local stimulation of prostaglandin production by corticotrophin releasing hormone in human fetal membranes and placenta Biochemical and Biophysical Research Communications $\mathbf{1 5 9} 192$

Jones SA, Brooks AN and Challis JRG (1989) Steroids modulate corticotropin-releasing hormone production in human fetal membranes and placenta Journal of Clinical Endocrinology and Metabolism 68 825-830

Korebrits C, Ramirez MM, Watson L, Brinkman E, Bocking AD and Challis JRG (1998) Maternal corticotropin-releasing hormone is increased with impending preterm birth Journal of Clinical Endocrinology and Metabolism 83 1585-1591

Kurki T, Laatikainen T, Salminen-Lappalainen K and Ylikorkala O (1991) Maternal plasma corticotrophin releasing hormone is elevated in preterm labour but unaffected by indomethacin or nylidrin British Journal of Obstetrics and Gynaecology 98 685-691

Laatikainen TJ, Raisanen IJ and Salminen KR (1988) Corticotropin releasing hormone in amniotic fluid during gestation and labor and in relation to fetal lung maturation American Journal of Obstetrics and Gynecology 159 891-895

Lenz HJ, Raedler A, Greten H and Brown MR (1987) CRF initiates biological actions within the brain that are observed in response to stress American Journal of Physiology 21 34-39

Leung TN, Chung TKH, Madsen G, McLean M, Chang AMZ and Smith R (1999) Elevated mid-trimester maternal corticotrophin-releasing hormone levels in pregnancies that delivered before 34 weeks British Journal of Obstetrics and Gynaecology 106 1041-1046

Linton EA, Perkins AV, Woods RJ, Eben F, Wolfe CDA, Behan DP, Potter E, Vale WW and Lowry PJ (1993) Corticotropin releasing hormone binding protein (CRH-BP): plasma levels decrease during the third trimester of normal human pregnancy Journal of Clinical Endocrinology and Metabolism 76 260-262

McLean M and Smith R (1999) Corticotropin-releasing hormone in human pregnancy and parturition Trends in Endocrinology and Metabolism $\mathbf{1 0}$ 174-178

McLean M, Thompson D, Zhang H-P, Brinsmead MW and Smith R (1994) Corticotropin-releasing hormone and beta-endorphin in labour European Journal of Endocrinology 131 167-172

*McLean M, Bisits A, Davies JJ, Woods R, Lowry PJ and Smith R (1995) A placental clock controlling the length of human pregnancy Nature Medicine 1 460-463

McLean M, Bisits A, Davies J, Walters W, Hackshaw A, De Voss K and Smith R (1999) Predicting risk of preterm delivery by second-trimester measurement of maternal plasma corticotropin-releasing hormone and alpha-fetoprotein concentrations American Journal of Obstetrics and Gynecology 181 207-215

Magiakou MA, Mastorakos G, Rabin D et al. (1996) The materna hypothalamic-pituitary-adrenal axis in the third trimester of human pregnancy Clinical Endocrinology 44 419-428

Margioris AN, Grino M, Protos P, Gold PW and Chrousos GP (1988) Corticotropin releasing hormone and oxytocin stimulate the release of placental pro-opiomelanocortin peptides Journal of Clinical Endocrinology and Metabolism 66 922-926

Mittendorf R, Williams MA, Berkey CS, Lieberman E and Monson RR (1993) Predictors of human gestational length American Journal of Obstetrics and Gynecology $\mathbf{1 6 8} 480-484$

Mongelli M and Opatola B (1995) Duration and variability of normal pregnancy. Implications for clinical practice Journal of Reproductive Medicine 40 645-648

Namba Y, Smith JB, Fox GS and Challis JRG (1980) Plasma cortiso concentrations during Caesarian sections British Journal of Anaesthesia 52 1027-1031

Nolten WE and Rueckert PA (1981) Elevated free cortisol index in pregnancy: possible regulatory mechanisms American Journal of Obstetrics and Gynecology 139 492-498

Nolten WE, Lindheimer MD, Rueckert PA, Oparil S and Ehrlich EN (1980) Diurnal patterns and regulation of cortisol secretion in pregnancy American Journal of Obstetrics and Gynecology 139 492-498

Okamoto E, Sugita N, Takaga T, Iwata I, Nishino E, Mitsuda N and Tanizawa O (1990a) Immunohistochemical analysis of corticotropinreleasing hormone $(\mathrm{CRH})$ in human trophoblast of normal pregnancy 
and hydatidiform mole Advances in Obstetrics and Gynecology 42 479-483

Okamoto E, Takagi T, Azuma C, Kimura T, Mitsuda N, Tokugawa Y, Saji F and Tanizawa $\mathbf{O}(1990 \mathrm{~b})$ Expression of the corticotropin-releasing hormone $(\mathrm{CRH})$ gene in human placenta and amniotic membrane Hormone and Metabolism Research 22 394-397

Perkins AV, Eben F, Wolfe CDA, Schulte HM and Linton EA (1993) Plasma measurements of corticotrophin-releasing hormone-binding protein in normal and abnormal human pregnancy Journal of Endocrinology 138 149-157

Petraglia F, Sawchenko PE, Rivier J and Vale W (1987) Evidence for local stimulation of ACTH secretion by corticotropin releasing factor in human placenta Nature 328 717-719

Petraglia F, Sutton S and Vale W (1989) Neurotransmitters and peptides modulate the release of immunoreactive corticotropin releasing factor from cultured human placental cells American Journal of Obstetrics and Gynecology $160247-251$

Petraglia F, Garuti GC, De Ramundo B, Angioni S, Genazzani AR and Bilezikjian LM (1990) Mechanism of action of interleukin-1 beta in increasing corticotropin-releasing factor and adrenocorticotropin hormone release from cultured human placental cells American Journal of Obstetrics and Gynecology 163 1307-1312

Petraglia F, Tabanelli S, Galassi MC, Garuti G, Mancini AC, Genazzani AR and Gurpide E (1992) Human decidua and in vitro decidualized endometrial stromal cells at term contain immunoreactive corticotropin releasing factor (CRF) and CRF messenger ribonucleic acid Journal of Clinical Endocrinology and Metabolism 74 1427-1431

Petraglia F, Genazzani AD, Aguzzoli L, Gallinelli A, de Vita D, Caruso A and Genazzani AR (1994) Pulsatile fluctuations of plasma gonadotropin-releasing hormone and corticotropin-releasing factor levels in healthy pregnant women Acta Obstetrica Gynecologica Scandinavia 73 284-289

Petraglia F, Florio P, Nappi C and Genazzani AR (1996) Peptide signaling in human placenta and membranes: autocrine, paracrine and endocrine mechanisms Endocrine Reviews 17 156-186

Quartero HWP and Fry CH (1989) Placental corticotrophin releasing factor may modulate human parturition Placenta 10 439-443

*Riley SC, Walton JC, Herlick JM and Challis JRG (1991) The localization and distribution of corticotropin-releasing hormone in the human placenta and fetal membranes throughout gestation Journal of Clinical Endocrinology and Metabolism 72 1001-1007

Robinson BG, Emanuel RL, Frim DM and Majzoub JA (1988) Glucocorticoid stimulates expression of corticotropin-releasing hormone gene in human placenta Proceedings National Academy of Sciences USA 85 5244-5248

Robinson BG, Arbiser JL, Emanuel RL and Majzoub JA (1989) Speciesspecific placental corticotropin-releasing hormone messenger RNA and peptide expression Molecular and Cellular Endocrinology 62 337-341

Saijonmaa O, Laatikainen T and Wahlstrom T (1988) Corticotrophinreleasing factor in human placenta: localization, concentration and release in vitro. Placenta $9373-385$

Saphier PW, Faria MS, Grossman AB, Coy DH, Besser GM, Hodson B, Parkes M, Linton EA and Lowry PJ (1992) A comparison of the clearance of ovine and human corticotropin-releasing hormone $(\mathrm{CRH})$ in man and in sheep: a possible role for CRH-binding protein Journal of Endocrinology 133 487-495

Sasaki A, Shinkawa O, Margioris AN, Liotta AS, Sato S, Murakami O, Go M, Shimizu Y, Hanew K and Yoshinaga K (1987) Immunoreactive corticotropin-releasing hormone in human plasma during pregnancy, labor and delivery Journal of Clinical Endocrinology and Metabolism 64 224-229

Sasaki A, Shinkawa O and Yoshinaga K (1990) Immunoreactive corticotropin-releasing hormone in amniotic fluid American Journal of Obstetrics and Gynecology 162 194-198

Schurmeyer TH, Avgerinos PC, Gold PW, Gallucci WT, Tomali TP, Cutler GB, Loriaux DL and Chrousos GP (1984) Human corticotropin- releasing factor in man: pharmacokinetic properties and dose-response of plasma adrenocorticotropin and cortisol secretion Journal of Clinical Endocrinology and Metabolism 59 1103-1108

Scott EM, McGarrigle HH and Lachelin GC (1990) The increase in plasma and saliva cortisol levels in pregnancy is not due to the increase in corticosteroid-binding globulin levels Journal of Clinical Endocrinology and Metabolism 71 639-644

*Shibasaki T, Odagirl E, Shizume K and Ling N (1982) Corticotrophin releasing factor-like activity in human placental extracts Journal of Clinical Endocrinology and Metabolism 55 384-386

Smith R, Cubis J, Chan E-C, Bowman ME, Harewood WJ and Phippard AF (1993) Corticotropin-releasing hormone in baboon pregnancy Journal of Clinical Endocrinology and Metabolism 76 1063-1068

Smith R, Mesiano S, Chan E-C, Brown S and Jaffe RB (1998) Corticotropinreleasing hormone directly and preferentially stimulates dehydroepiandrosterone sulfate secretion by human fetal adrenal cortical cells Journal of Clinical Endocrinology and Metabolism 83 2916-2920

Smith R, Wickings EJ, Bowman ME, Belleoud A, Dubreuil G, Davies JJ and Madsen G (1999) Corticotropin-releasing hormone in chimpanzee and gorilla pregnancies Journal of Clinical Endocrinology and Metabolism $842820-2825$

Stalla GK, Bost H, Stalla J, Kaliebe T, Dorr HG, Pfeiffer D, von Werder K and Muller OA (1989) Human corticotrophin releasing hormone during pregnancy Gynecological Endocrinology 3 1-10

Suda T, Tomori N, Tozawa F, Mouri T, Demura H and Shizume K $(1984$ Distribution and characterisation of immunoreactive corticotropinreleasing factor in human tissues Journal of Clinical Endocrinology and Metabolism 55 861-866

Sun K, Smith R and Robinson PJ (1994) Basal and KCl stimulated corticotropin releasing hormone release from human placental syncytiotrophoblasts is inhibited by sodium nitroprusside Journal of Clinical Endocrinology and Metabolism 79 519-524

Ulisse S, Fabbri A, Tinajero JC and Dufau ML (1990) A novel mechanism of action of corticotropin releasing factor in rat Leydig cells Journal of Biological Chemistry 265 1964-1971

*Vale W, Spiess J, Rivier C and Rivier J (1981) Characterization of a 41residue ovine hypothalamic peptide that stimulates secretion of corticotropin and B-endorphin Science 213 1394-1397

Warren WB, Patrick SL and Goland RS (1992) Elevated maternal plasma corticotropin releasing hormone levels in pregnancies complicated by preterm labour American Journal of Obstetrics and Gynecology $\mathbf{1 6 6}$ 1198-1207

Wintour EM, Bell RJ, Carson RS, Maclsaac RJ, Tregear GW, Vale W and Wang X-M (1986) Effect of long term infusion of ovine corticotrophin releasing factor in the immature ovine fetus Journal of Endocrinology 111 469-475

Wolfe CDA, Patel SP, Campbell EA, Linton EA, Anderson J, Lowry PJ and Jones MT (1988a) Plasma corticotrophin releasing factor (CRF) in normal pregnancy British Journal of Obstetrics and Gynaecology 95 997-1002

Wolfe CDA, Patel SP, Linton EA, Campbell EA, Anderson J, Dornhorst A, Lowry PJ and Jones MT (1988b) Plasma corticotrophin-releasing factor (CRF) in abnormal pregnancy British Journal of Obstetrics and Gynaecology 95 1003-1006

Wolfe CDA, Petruckevitch A, Quartero R, Carabelli P, Poston L, Kerkez S, Campbell E, Lowry PJ and Linton EA (1990) The rate of rise of corticotrophin releasing factor and endogenous digoxin-like immunoreactivity in normal and abnormal pregnancy British Journal of Obstetrics and Gynaecology 97 832-837

Woods RJ, Kennedy KM, Gibbins JM, Behan DP, Vale W and Lowry PJ (1994a) Corticotropin-releasing factor binding protein dimerizes after association with ligand Endocrinology 135 768-773

Woods RJ, Grossman A, Saphier P, Kennedy K, Ur E, Behan DP, Potter E, Vale W and Lowry PJ (1994b) Association of human corticotropinreleasing hormone to its binding protein in blood may trigger clearance of the complex Journal of Clinical Endocrinology and Metabolism 78 73-76 